УДК 316

$10.17213 / 2075-2067-2020-4-140-149$

\title{
ЭКОЛОГИЧЕСКИЕ ПРАКТИКИ В СИСТЕМЕ СОЦИАЛИЗАЦИИ СОВРЕМЕННОЙ РОССИЙСКОЙ МОЛОДЁЖИ
}

\author{
(C) 2020 г. B. A. Захарова \\ Крымский филиал Федерального научно-исследовательского \\ социологического центра РАН, г. Симферополь, Россия
}

Целью исследования является исследование экологических практик в системе соичализации современной российской молодёжи.

Методологическую базу исследования представляют классические социологические теории (Э. Дюркгейм, М. Вебер и др.), культурсочиология (Дж. Александер) и рискологический подход (У. Бек).

Результаты исследования. Экологические практики в целом соответствуют уровню развития экологической культуры в стране, которая, однако, может различаться в зависимости от региона. Более того, в наиболее неблагополучных с точки зрения экологии регионах экологические практики молодёжи будут не столь эффективными по своему социиальному воздействию или могут сводиться просто к минимизации и избеганию дополнительных рисков. Сложившаяся ситуация свидетельствует в пользу того, что молодёжь ещё необходимо заинтересовать экологической проблематикой. Командная работа по профилактике экологической безопасности и мониторингу окружающей среды в собственном регионе или районе приучает молодых людей к сотрудничеству в решении актуальных экологических проблем.

Перспективу исследования составляет дальнейшее развитие экологических практик современной российской молодежи.

Ключевые слова: молодежь; экологическое поведение; экологичские практики; регион; общество; культура.

\section{ENVIRONMENTAL PRACTICES IN THE SYSTEM OF SOCIALIZATION OF MODERN RUSSIAN YOUTH}

(C) 2020 V. A. Zakharova

\section{Crimean Branch of the Federal Research Sociological Center, Russian Academy of Sciences, Simferopol, Russia}

The purpose of the research is to study environmental practices in the system of socialization of modern Russian youth.

The methodological basis of the research is represented by classical sociological theories (E. Durkheim, M. Weber, etc.), cultural sociology (J. Alexander) and the risk approach (W. Beck).

Research result. Environmental practices generally correspond to the level of development of environmental culture in the country, which, however, may differ depending on the region. Moreover, in the most environmentally disadvantaged regions, the environmental practices of young people will not be as effective in their social impact, or may simply be reduced to minimizing 
and avoiding additional risks. The current situation shows that young people still need to be interested in environmental issues. Teamwork to prevent environmental safety and monitor the environment in their own region or district trains young people to cooperate in solving urgent environmental problems.

The perspective of the research is the further development of environmental practices of modern Russian youth.

Key words: youth; ecological behavior; ecological practices; region; society; culture.

Введение. Изучая экологическое поведение российской молодёжи в контексте его ценностного и социокультурного измерения, необходимо рассмотреть социальные практики, которые могут быть реализованы в сфере экологического взаимодействия человека и природы, а также мобилизации населения под знаком природоохранной деятельности. Значительная часть подобных практик организуется совместно с институтами и органами управления, в связи с чем следует говорить о необходимости постоянного вовлечения молодых людей в деятельность природоохранного характера. С другой стороны, экологические практики могут распространяться на гигиенические и потребительские аспекты жизнедеятельности современного человека, а также составлять неотъемлемый компонент его свободного времяпровождения, то есть времени досуга.

В современном обществе экономика уже не существует как автономная сфера приложения человеческих сил, она должна коррелировать с требованиями глобального экологического развития, поэтому экологические практики российской молодёжи в сфере потребления, а не только практики, рассматриваемые в контексте природоохранной деятельности, имеют также существенное значение для предмета нашего исследования. Соответственно и потребители стремятся использовать продукты, соответствующие быстрорастущим экологоцентричным стандартам. Молодёжь находится в первых рядах социальных агентов, осваивающих международные экологические стандарты в своей повседневной жизни, особенно те из них, которые связаны с источниками энергии, в меньшей степени угрожающими природе. Применительно к экологическим практикам необходимо говорить о высоком уровне их социальной интеграции, включенности в общественную жизнь и высоком уровне осознанности. Только при соблюдении всех этих условий можно говорить о систематичности подобных практик. В противном случае социальные практики молодёжи, особенно в среде представителей молодёжных субкультур, способны вступать в противоречие и даже конфликт с государственными планами социального развития. Последнее особенно актуально в условиях глобального карантина и усиления вирусных угроз, когда резко возрастает индивидуальная ответственность людей, как за собственное здоровье, так и здоровье окружающих.

Специфика реализации экологических практик современной российской молодёжи. Экологические практики молодёжи в сфере потребления товаров и услуг можно разделить в принципе на несколько уровней, первый из которых базируется на предпочтении непосредственно более «экологичных», «чистых» товаров или, по крайней мере, товаров, считающихся в потребительской среде наиболее «экологическими». Первый уровень экологического потребления имеет дело с непосредственным товаром или услугой, но на нём потребитель не интересуется процессом его производства и соблюдением при этом соответствующих экологических норм. «Более высокий уровень экологизации - это предпочтение товаров, произведенных без нанесения ущерба среде или обещающих быстрый распад после использования. Наконец, экологически сознательные потребители отдают предпочтение товарам, произведенным фирмами, известными как производства, участвующие в экологизации, хотя с конкретным товаром это и не было бы связано» [1]. Таким образом, следующий более высокий 
уровень экологического потребления предполагает высокую информированность молодёжи не только о самих товарах или даже известных брендах, но и о компаниях-производителях и далее об экологическом имидже этих самых корпораций. В данной связи важно обратить внимание на то, что для реализации подобных практик молодые люди должны обладать довольно высоким уровнем знаний о мировой экономике.

Прогулки на свежем воздухе в условиях, воспроизводящих природное окружение, также являются важным сегментом экологических практик современной молодёжи, хотя далеко не все представители данной группы придают им первостепенное досуговое значение. На этом фоне очевидно, что далеко не все городские агломерации способны предложить всем своим жителям развитые парковые и рекреационные зоны, строительство которых правда, довольно часто ведётся вокруг крупных торговых центров. Однако, разочарованность городской культурой в целом и особенно в крупных городах с очевидными экологическими проблемами может подтолкнуть молодых людей к поиску практических средств преодоления негативных последствий «постиндустриального» общества. Вместе с тем имеющиеся в распоряжении молодёжи культурные практики не способны в полной мере обеспечить выход из депрессивного состояния, не в последнюю очередь связанного с трудностями социальной интеграции. Таким образом, подобные практики являются необходимым маркером определения уровня качества жизни для граждан большинства стран современного мира.

Стандарты общества потребления в свою очередь могут не только распространяться в молодёжной среде, но и оказывать непосредственное влияние на экологические практики, которые характерны, скорее, не для молодёжи, а для представителей в большей степени устроенных и состоятельных социальных групп населения. Вместе с тем в настоящее время речь уже практически не идёт об (утопическом) проекте полного отказа от массового потребления, а напротив, о компромиссной интеграции экологических и консюмеристских практик в культуру современной молодёжи. Так, например, исследователи справедливо отмечают, что «желание иметь собственное дерево и идентифицировать себя с группой людей, озадаченных вопросами охраны окружающей среды, можно расценивать как ответ на развитие постматериалистических ценностей, приобретение которых наиболее экономически обеспеченные граждане имеют возможность оплачивать» [2]. Мода на экологизм, как и стремление к обретению и поиску друзей и брачных партнеров, является наиболее значимой задачей социализации, поэтому с другой стороны от большинства молодых людей не стоит ожидать «слишком серьёзного» отношения к глобальным экологическим проблемам, учитывая игровой характер их восприятия социальных процессов.

При этом, однако, молодые люди могут вполне выступать как защитники окружающей среды, к тому же они значительно реже способны осуществлять инвестиции в экологический дизайн, например, украшая собственный сад. Другое дело, что экологические практики молодёжи могут носить акционистский и даже протестный характер, что не в последнюю очередь связано с особенностью их темперамента (несмотря на романтизм, молодые люди редко воспринимают окружающую природную среду как «уютное гнездышко», в котором они желают обустроиться). Это не значит, что молодые люди не желают участвовать в позитивных отношениях с окружающей средой, это особенно касается животных, которых многие представители молодёжи склонны воспринимать как «равных» (братьев) партнеров по биотическому существованию.

В целом экологические практики молодёжи должны быть усовершенствованы в зависимости от требований, которые предъявляет к обществу модернизация экономики и социальной сферы. «Современные процессы модернизации, - как отмечают отечественные исследователи, - очевидно вступают в противоречие с ценностной системой российского общества, что приводит людей к разочарованию и индифферентному отношению к меняющейся в результате социальной среде и городской инфраструктуре. Еще хуже с настроением населения обстоят дела в тех городах, где модернизационных процессов по сути не происходит, зато массово появляются имитаторы модернизации в виде 
большого числа торговых центров, которые постепенно становятся основными местами проведения досуга, подменяя собой все культурные учреждения» [3]. В данной связи можно вполне говорить о том, что экологические практики должны насколько это возможно заменять активные формы досуга молодёжи, собственно выступая практиками свободного (экологического) времяпрепровождения.

Учитывая, какую важную роль в жизни молодых людей занимает досуг, необходимо отметить, что в российском обществе попрежнему наблюдается дефицит оздоровительных практик, способных в свою очередь выполнять в обществе как природоохранные, так и эстетические функции. Несомненно, что экологические практики не будут в должной степени эффективными, если при их внедрении в молодёжную среду будет иметь место принуждение, поэтому в первую очередь необходимо ориентироваться на креативную молодёжь. Таким образом, креативность, то есть «готовность к социальному действию, ориентированному на созидание общества» [4], должна лежать в основе экологических практик, направленных на раскрытие субъектности современной молодёжи. Другое дело, что многие молодые люди по-прежнему воспринимают различного рода экологическую деятельность, куда их вовлекают муниципальные органы власти, как «казенные» мероприятия, в рамках которых региональные власти желают всего лишь «отчитаться перед вышестоящим начальством об успешно проделанной работе».

Игровые формы реализации экологических практик молодёжи занимают привилегированное положение в системе экологической социализации, поскольку выходят за пределы скучной рутины и помогают обнаружить новые резервы для собственной идентичности. Раскрытие личностного потенциала молодого человека также может происходить в природных условиях, что может привести к обнаружению ресурсов ума и организма, которые не были востребованы в городских условиях, поэтому в целом молодым людям требуется отдых от цивилизации, вдали от интернета, планшетов и смартфонов. Правда, сам по себе такой отдых может восприниматься представителями молодёжи уже как форма экстремального туризма (вглубь природы), однако именно в подобных условиях молодые люди смогут оценить экологическую ситуацию изнутри, на практике «породнившись» с природой, они смогут воспринять её как богатство, требующее сохранения ради будущих поколений.

Важно отметить, что экологические практики молодёжи не бывают абстрактными в том смысле, что они не учитывают локальные и региональные особенности природоохранной и природосбегающей деятельности, поэтому экологические практики в значительной степени связаны с патриотическими установками современной молодёжи, особенно теми из них, которые напрямую связаны с понятием «малой родины». С заинтересованности в экологическом благополучии собственного края начинается ответственное экологическое поведение молодёжи, не заинтересованной в эмиграции в другие регионы и страны, обладающие большей экологической привлекательностью. При этом важно начать обустройство своего природного окружения самым актуальным образом, даже в отсутствии систематической помощи со стороны государства. «Любовь к своему месту жительства (т.е. патриотизм) главным образом проявляется там, где элементы модернизации не отменяют насильственно действующие традиции. Такие города, где, наоборот, традиции поддерживаются и развиваются, иногда преобразовываются в соответствии с инновациями, которые проникают в нашу жизнь, и процесс этот объективный, а не искусственный» [3]. Таким образом, экологические практики молодёжи находятся в постоянной коннекции с другими сегментами общественной жизни.

Важным условием распространения и внедрения экологических практик в России среди представителей молодёжи является их добровольность, поэтому, на наш взгляд, ключевую роль в создании и продвижении экологических практик молодёжи играют волонтерские сообщества и организации. Именно они выступают посредниками между молодыми людьми и государством, так сказать, аккумулируя в себе как вертикальные, так и горизонтальные связи. В пункте активной деятельности волонтерских организаций в наиболее полной мере может быть реализовано сотрудничество между государством 
и институтами гражданского общества. При этом государственное финансирование подобных организаций по-прежнему оставляет много вопросов, связанных с прозрачностью необходимых бюджетных расходов.

Вместе с тем для финансирования волонтерского экологического движения необходимо привлекать средства частных инвесторов, заинтересованных в формировании позитивного образа своих корпораций внутри страны. Однако, в России искомого результата не всегда возможно добиться без решительной позиции и «принуждения» крупных корпораций со стороны государства. Дополнительные трудности также связаны с тем, что большинство российских корпораций либо официально являются государственными компаниями, активно реализующими национальные проекты, либо очень сильно аффилированы с представителями высшей бюрократии. При этом важно признать, что включение отечественного бизнеса в экологические проекты довольно сильно ограничено нахождением России под целым рядом западных (экономических) санкций, серьёзно препятствующих внедрению в экономику более совершенных экологических технологий. Не секрет, что и сильная зависимость экономики страны от экспорта углеводорода также существенно блокирует перспективы массовой экологизации современного российского общества.

Роль государства в развитии и социальной поддержке экологических практик молодёжи. В контексте государственного управления и правового регулирования экологических проблем уже пришло осознание проведения соответствующих политических реформ, направленных на предоставление регионам страны большей свободы в плане мониторинга и решения экологических проблем, исходя из собственной (региональной) специфики и имеющихся ресурсов. Для этого необходимо ещё в большей степени привлекать местную молодёжь к природоохранной деятельности, тем самым закладывая дополнительную основу под фундамент регионального патриотизма.

Экологические практики молодёжи обладают серьёзными перспективами дальнейшего развития в связи с осознанием проблем загрязнения окружающей среды и разрушением биотической инфраструктуры на государственном уровне. «К настоящему моменту Россия уже провела ряд политических реформ в сфере государственного управления охраной окружающей среды. Была принята серия федеральных законодательных актов, а также политические инициативы, включающие ряд решений, направленных на формирование экономического инструментария, децентрализацию и передачу властных полномочий на региональный уровень, повышающие информированность гражданского общества и более широкое участие в осуществлении природоохранных мероприятий» [5]. При этом сами по себе экологические практики молодёжи должны восприниматься государством и обществом как направленные инвестиции в человеческий капитал.

Молодёжь также должна рассматривать экологическое движение как перспективное для построения собственной успешной карьеры и возможной легальной политической социализации в рамках отведенных законодательством и конституцией страны. На этом фоне исследователи фиксируют определенный рост интереса к экологическим практикам, которые могут вовлечь молодёжь в природоохранную деятельность, повысив качество управления экологическими процессами на местах [6]. В данной связи также важно определиться с лидерами молодёжного экологического движения, чтобы сделать его в ближайшей перспективе в России довольно массовым и конкурентоспособным социальным явлением.

Давление неблагоприятной экологической обстановки в стране в целом в сочетании с влиянием глобальных трендов обеспечения экологической безопасности в принципе оказывает воздействие на актуализацию российского экологического движения. «Сегодня в России наблюдается новый период роста численности и активности общественного экологического движения (по-прежнему в значительной мере природоохранного), увеличивается разнообразие форм существования и направлений деятельности, что связано с переосмыслением его роли в системе государственных органов власти, появлением новых активных лидеров» [5]. Вместе с тем для стабильности страны будет прием- 
лемым избежать рисков, связанных с оппозиционной политической активностью лидеров молодёжного экологического движения и оппозиционных настроений, в целом набирающих силу на фоне экономической стагнации и сокращения доходов населения.

Подготовка к Сочинской Олимпиаде-2014 и её проведение на высоком уровне запустили крупномасштабный процесс институционализации волонтерского (преимущественно молодёжного) движения в нашей стране. На федеральном уровне 29.11.2014 г. были утверждены «Основы государственной молодежной политики Российской Федерации на период до 2025 года», в которых даны правовые установки добровольческой (волонтерской) деятельности. Данный вид социальной активности фиксируется в документах как «добровольная социально направленная и общественно полезная деятельность молодых граждан, осуществляемая путем выполнения работ, оказания услуг без получения денежного или материального вознаграждения (кроме случаев возможного возмещения связанных с осуществлением добровольческой (волонтерской) деятельности затрат)» [7]. Основными сформулированными в документе целями молодёжной политики является совершенствование социально-экономических, организационных и правовых условий развития молодёжи, раскрытия её творческого потенциала, гарантирующие успешную интеграцию в общество и усиление её роли в жизни страны.

Таким образом, добровольческая (волонтерская) деятельность выступает одним из таких центральных пунктов молодёжной политики, которая направлена на привлечение молодёжи в значимые для страны проекты, а также социализации представителей данной группы на основе практической реализации гражданских ценностей. Однако при этом нельзя упускать из виду личностный уровень социализации молодых людей в современном информационном обществе. Наличие в распоряжении граждан современных информационных технологий позволяет им самостоятельно осуществлять мониторинг экологических проблем и самим выступать в роли источников подобной информации. В данной связи важно учитывать, что личностная заинтересованность молодых людей в экологических мероприятиях связана часто с желанием общаться, поиском близким людей, устройством любовной жизни, тогда как для представителей старшего поколения экологические практики в большей степени связаны с работой и профессиональной карьерой. В контексте всего вышеизложенного мы полагаем, что необходимо закрепить правовой статус экологических практик молодёжи, чтобы в дальнейшем избежать их радикализации в сторону возможного экологического (субкультурного) экстремизма. Ведь для того, чтобы быть ответственным субъектом в сфере экологической политики, не обязательно отрицать достижения цивилизации и становиться в жесткую оппозицию по отношению к действующей власти.

Вместе с тем само государство должно создавать адекватные экологические программы, способные рекрутировать в свои ряды именно увлеченных данной проблематикой людей. В данной связи исследователи отмечают, что трудно «не учитывать, что в молодежном возрасте жизненные цели только формируются и осознание значимости инновации для развития личности молодого человека и продвижения общества вперед в какой-то систематической форме еще не может сложиться, если только нет столь мощных факторов быстрого взросления, которые целое поколение способны освободить от инфантильности в определении жизненных целей (война, революция и т.д.)» [8]. В современном российском обществе, однако, пока не обнаруживается факторов (резких или даже экстремальных), способствующих быстрому взрослению молодёжи, тем более, учитывая высокий уровень инфантилизации социума в целом, что также отражает общемировые тенденции, поэтому перед институтами социализации по-прежнему стоит задача сделать рассматриваемые практики привлекательными и порой просто интересными для представителей молодёжи всех возрастов. Важно переключить внимание молодёжи с гаджетов на проблемы, возникающие при эксплуатации природы, и взаимоотношения с окружающей средой в повседневной жизни.

Очевидно, что экологические практики молодёжи являются во многом инновационными и способствуют становлению новых экономических трендов [9]. Экологические 
практики могут способствовать накоплению и развитию человеческого капитала, выступать важным средством сбережения как природных, так и человеческих ресурсов. «Современные экономика и общество в развитых странах все в большей степени становятся креативными (творческими), главными продуктами которых являются новые идеи и инновации в различных областях деятельности. Человеческий капитал становится основным источником экономического развития и мирового лидерства. Успешность стран будет обуславливаться качеством граждан, интеллектуального, духовного и морального состояния общества. Вызовом для России является переход с сырьевого сценария развития экономики на построение инновационной экономики, основанной на знаниях» [7]. Сложно представить возможный уход от реализации сырьевого сценария в отечественной экономике без сопровождения возможных инноваций экологическими практиками молодёжи, которые выступают основой их социального и инновационного развития.

Курортные регионы страны, особенно расположенные на побережье, имеют определенные преимущества внедрения экологических практик в молодёжную среду, поскольку молодые люди способны проводить свои (согласованные с региональным правительством) мероприятия в благоприятных климатических условиях. К тому же рекреационные ресурсы, которыми располагают курорты, обладают особой, в том числе и коммерческой ценностью, существенно предохраняющей их от хищнического использования и истощения. Активная работа с молодёжью в плане приобщения их к экологическому мониторингу и природоохранным практикам постоянно проводится в республике Крым. Так, например, «указом главы Крыма Сергея Аксёнова утверждено положение «О формировании Молодежного актива PK. В соответствии с Положением, приказом Министерства образования, науки и молодежи Республики Крым утверждён состав Молодежного актива РК, одним из направлений деятельности которого является экология» [10]. Таким образом, региональная специфика эксплуатации природных ресурсов может оказаться определяющей для каждого отдельного случая. Ясно, что, например, на территории РК экологические практи- ки и природоохранная деятельность молодёжи будут существенно сопрягаться с региональным развитием уже имеющейся туристической отрасли.

Внедрение экологических практик, как правило, осуществляется при посредстве массированной просветительской деятельности. Поиск лидеров из среды молодёжного движения является наиболее важной частью проведения экологических мероприятий. «В рамках проведения акции среди учащихся образовательных организаций будут проведены республиканская научно-практическая конференция «Проблемы охраны окружающей среды» и конкурс «Лучший социальный ролик на природоохранную тематику». Образовательные организации смогут принять участие в республиканском социально-образовательном проекте лидеров экологического движения «Я, Ты, Он, Она - вместе мы ЭКОстрана!» [11]. В целом подобные практики привлечения молодёжи в ряды экологического движения могут рассматриваться как праздничные мероприятия, посвященные успехам природоохранной деятельности в регионе.

Можно констатировать, что особенно тяжело внедряются подобные практики в тех регионах, где выгоды от экологического поведения не столь очевидны, но притом являются довольно затратными с точки зрения времени и материальных расходов. «Осознание человеком необходимости рационального использования природных ресурсов еще не гарантирует того, что подобное поведение будет реализовано им на практике. Определенная неконгруэнтность наблюдается и между отношением молодежи к новой системе утилизации отходов в Краснодарском крае и готовностью нести ради нее дополнительные затраты» [12]. К тому же в массовом сознании современных россиян по-прежнему сильно убеждение, что именно государство и соответствующие службы (получающие отдельное финансирование) должны заботиться об экологической ситуации, тогда как гражданское общество, скорее, должно брать на себя функции надзора и контроля над исполнением задач муниципальных и региональных учреждений.

Заключение. Экологические практики в отличие от социально-экологических дейс- 
твий обладают устойчивым и повторяющимся характером, хотя и действуют на микросоциологическом уровне интеракций. Экологические практики молодёжи таким образом представляют собой институциализированный и довольно систематический тип социальной активности, направленной на минимизацию рисков, связанных с загрязнением окружающей среды и последствиями загрязнений, представляющих угрозу для жизни и здоровья [13], причем, несмотря на своё разнообразие, экологические практики в целом соответствуют уровню развития экологической культуры в стране, которая, однако, может различаться в зависимости от региона. Более того, в наиболее неблагополучных с точки зрения экологии регионах экологические практики молодёжи будут не столь эффективными по своему социальному воздействию или могут сводиться просто к минимизации и избеганию дополнительных рисков. Таким образом, когда мы изучаем экологические практики молодежи, мы упираемся в потолок их компетентности в плане возможности реализации тех или иных природоохранных программ.

Молодёжь является группой, довольно чувствительной к ограничению свободы и «навязыванию» каких-либо (пускай и справедливых) мнений, что подчеркивает необходимость отказа от чрезмерного «давления» на представителей рассматриваемой группы (причём важно учитывать мнение самих молодых людей по данному спектру вопросов, что в свою очередь могут обеспечить сами представители молодёжи, задействованные в экспертном сообществе и муниципальных органах управления). Тем не менее, молодые люди остро нуждаются в социальной поддержке, которая может быть комплементарной присущему им чувству свободы. Не секрет, что в данной связи молодые люди нуждаются в понимании и доверии со стороны представителей старшего поколения. Исследователи в целом согласны с распространенным мнением, что вовлечение представителей молодёжи в экологические практики во многом представляет собой разновидность социальной поддержки [14]. Порой оказывается важным просто занять молодых людей полезной практикой, что может существенно снизить в их среде риски девиантного поведения.
Таким образом, сложившаяся ситуация свидетельствует в пользу того, что молодёжь ещё необходимо заинтересовать экологической проблематикой. К тому же чем в большей степени мы имеем дело с молодёжью из наиболее юных возрастов, тем более важную роль в процессе их вовлечения в экологические практики занимает игровой аспект подобной деятельности. Командная работа по профилактике экологической безопасности и мониторингу окружающей среды в собственном регионе или районе приучает молодых людей к сотрудничеству в решении актуальных экологических проблем.

\section{Литература}

1. Якобсон А. Я., Бацฺюн Н. В. Экологические аспекты качества жизни // Вестник Иркутского государственного технического университета. - 2014. - №5 (88). - С. 211-215.

2. Тарасова О.Н. Социальные практики экологической культуры молодёжи: изучение случаев участия в экологических мероприятиях // Мир современной науки. - 2013. №5 (20). - С. 96-105.

3. Халий И.А. Модернизация и патриотизм: есть ли между ними связь? // Гуманитарий Юга России. - 2017. - №3. - С. 50-62.

4. Волков Ю.Г. Креативность: исторический прорыв России. - М.: Социально-гуманитарные знания, 2011. - 104 с.

5. Токарев А.С. Практика взаимодействия политических институтов и экологического движения в России // Власть. - 2017. T. 25. - №8. - С. 90-95.

6. Финогентова А.В., Ситникова Е.М. Совершенствование системы государственного обеспечения качества окружающей среды// Сервис в России и за рубежом. - 2019. T. 13. 一 №2 (84). - С. 83-94.

7. Основы государственной молодежной политики Российской Федерации на период до 2025 года (утв. распоряжением Правительства РФ от 29 ноября 2014 г. №2403-р). ГЭлектронный ресурс]. - Режим доступа: http:// www.fadm.gov.ru/docs/9/. (Дата обращения: 28.02.2020 г.).

8. Луков Вал. А. Биосоциология молодежи: теоретико-методологические основания: науч. монография. - М.: Изд-во Моск. гуманит. ун-та, 2013. - 244 с. 
9. Медведев: цифровая экономика требует корректировкизаконодательства (2017)[Электронный ресурс] // ТАСС. 27 июня. - Режим доступа: http://tass.ru/ ekonomika/4368611 [apхивировано в WaybackMachine]. (Дата обращения: 14. 06.2020 г.).

10. Молодежь Крыма проявляет активную жизненную позицию в вопросах охраны окружающей среды республики [Электронный ресурс]. - Режим доступа: https://crimea.kz/332766-Molodezh-Krymaproyavlyaet-aktivnuyu-zhiznennuyu-poziciyuv-voprosah-ohrany-okruzhayusheiy-sredy respubliki-Sologub.html. (Дата обращения: 27.02.2020 г.).

11. Акция «Крым - регион экологической безопасности и чистоты» [Электронный pecypc]. - Режим доступа: https://crimeanews.com/society/2020/02/15/610030.html. (Дата обращения: 14.06.2020 г.).

12. Пупкова Ю.В. Отношение молодёжи к проэкологическим практикам раздельного сбора твердых коммунальных отходов // Общество: социология, психология, педагогика. - 2019. - №4 (60). - С. 41-46.

13. Захарова Е. Ю. Экологическая культура соционатурэкосистемы: Автореф. дис.... д-ра философ. наук. - Чита, 2012. - 39 с.

14. Некрасова Е.Г. Институциональные практики реализации поддержки молодёжи на государственном уровне в современной России // Гуманитарий Юга России. 2017. — T. 23. - №1. - C. 101-110.

\section{References}

1. Jakobson A. Ja., Bacjun N.V. Jekologicheskie aspekty kachestva zhizni [Environmental aspects of quality of life] // Vestnik Irkutskogo gosudarstvennogo tehnicheskogo universiteta [Bulletin of Irkutsk State Technical University]. - 2014. — №5 (88). — Pp. 211-215.

2. Tarasova O.N. Social'nye praktiki jekologicheskoj kul'tury molodjozhi: izuchenie sluchaev uchastija $\mathrm{v}$ jekologicheskih meroprijatijah [Social practices of ecological culture of youth: the study of cases of participation in environmental events] // Mir sovremennoj nauki [World of modern science]. — 2013. №5 (20). — Pp. 96-105.

3. Halij I. A. Modernizacija i patriotizm: est' li mezhdu nimi svjaz'? [Modernization and pa- triotism: is there a connection between Them?]// Gumanitarij Juga Rossii [Humanities of the South of Russia]. - 2017. - №3. - Pp. 50-62.

4. Volkov Ju. G. Kreativnost': istoricheskij proryv Rossii [Creativity: historical breakthrough of Russia]. - Moscow: Social'no-gumanitarnye znanija, 2011. - $104 \mathrm{p}$.

5. Tokarev A.S. Praktika vzaimodejstvija politicheskih institutov i jekologicheskogo dvizhenija $v$ Rossii [Practice of interaction of political institutions and environmental movement in Russia] // Vlast' [Power]. — 2017. Vol. 25. - №8. - Pp. 90-95.

6. Finogentova A. V., Sitnikova E.M. Sovershenstvovanie sistemy gosudarstvennogo obespechenija kachestva okruzhajushhej sredy [Improving the system of state environmental quality assurance] // Servis v Rossii i za rubezhom [Service in Russia and abroad]. — 2019. Vol. 13. — №2 (84). — Pp. 83-94.

7. Osnovy gosudarstvennoj molodezhnoj politiki Rossijskoj Federacii na period do 2025 goda (utv. rasporjazheniem Pravitel'stva RF ot 29 nojabrja 2014 g. №2403-r) [Fundamentals of the state youth policy of the Russian Federation for the period up to 2025 (approved by the decree of the Government of the Russian Federation of November 29, 2014 №2403-r)] [Jelektronnyj resurs]. — URL: http://www.fadm.gov. ru/docs/9/. (Date accessed: 28.02.2020).

8. Lukov Val. A. Biosociologija molodezhi: teoretiko-metodologicheskie osnovanija: nauch. monografija [Biosociology of youth: theoretical and methodological foundations: scientific monograph]. - Moscow: Izd-vo Mosk. gumanit. unta, 2013. $-244 \mathrm{p}$.

9. Medvedev: cifrovaja jekonomika trebuet korrektirovki zakonodatel'stva [Medvedev: digital economy requires adjustment of legislation] (2017) [Jelektronnyj resurs] // TASS. June 27. — URL: http://tass.ru/ ekonomika/4368611 [arhivirovano v WaybackMachine]. (Date accessed: 14. 06.2020).

10. Molodezh' Kryma projavljaet aktivnuju zhiznennuju poziciju $\mathrm{v}$ voprosah ohrany okruzhajushhej sredy respubliki [The Youth of the Crimea shows an active life position in the issues of environmental protection of the Republic] [Jelektronnyj resurs]. — URL: https:// crimea.kz/332766-Molodezh-Kryma-proyavlyaet-aktivnuyu-zhiznennuyu-poziciyu-v-voprosah-ohrany-okruzhayusheiy-sredy respublikiSologub.html. (Date accessed: 27.02.2020). 
11. Akcija «Krym — region jekologicheskoj bezopasnosti i chistoty» [Action «Crimea - region of ecological safety and cleanliness»)] [Jelektronnyj resurs]. - URL: https://crimea-news. com/society/2020/02/15/610030.html. (Date accessed: 14.06.2020).

12. Pupkova Ju. V. Otnoshenie molodjozhi $\mathrm{k}$ projekologicheskim praktikam razdel'nogo sbora tverdyh kommunal'nyh othodov [Attitude of young people to Pro-environmental practices of separate collection of solid municipal waste]// Obshhestvo: sociologija, psihologija, pedagogika [Society: sociology, psy- chology, pedagogy]. — 2019. — №4 (60). Pp. 41-46.

13. Zaharova E. Ju. Jekologicheskaja kul'tura socionaturjekosistemy [Ecological culture of socionaturekosistemy: Dr. Sci. (Philosophy) Thesis]. - Chita, 2012. - 39 p.

14. Nekrasova E. G. Institucional'nye praktiki realizacii podderzhki molodjozhi na gosudarstvennom urovne v sovremennoj Rossii [Institutional practices of implementing youth support at the state level in modern Russia] // Gumanitarij Juga Rossii [Humanities of the South of Russia]. — 2017. — Vol. 23. — №1. - Pp. 101-110.

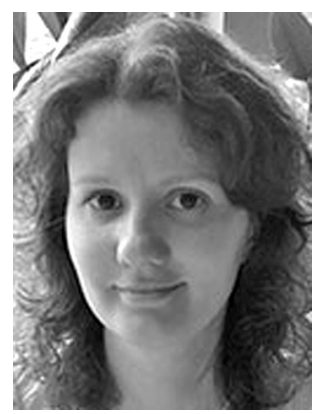

Захарова Вера Александровна - кандидат философских наук, старший научный сотрудник Крымского филиала Федерального научно-исследовательского социологического центра Российской академии наук. Специалист в области исследования экоправового воспитания, экологических практик и экологического поведения. Соисполнитель ряда региональных социологических исследований.

Zakharova Vera Alexandrovna - Candidate of Philosophical Sciences, Senior Researcher, Crimean Branch of the Federal Research Sociological Center, Russian Academy of Sciences. Specialist in the field of environmental education research, environmental practices and environmental behavior. Co-executor of a number of regional sociological studies.

295021, г. Симферополь, ул. им. газеты «Крымская правда», 4 4 st. Name of the Newspaper «Crimean Truth», 295021, Simferopol, Russia

E-mail: zakharova7vera@mail.ru 